\title{
Models of the user: designers' perspectives on influencing sustainable behaviour
}

\section{Dan Lockton* and David Harrison}

Cleaner Electronics Research Group, Brunel Design, Brunel University, Uxbridge, Middlesex UB8 3PH, UK E-mail: daniel.lockton@brunel.ac.uk E-mail: David.Harrison@brunel.ac.uk *Corresponding author

\section{Neville A. Stanton}

Transportation Research Group, School of Engineering and the Environment, University of Southampton,

Hampshire, SO17 1BJ, UK

E-mail: N.Stanton@soton.ac.uk
This is an author-archived pre-print version of this article, as permitted by Inderscience's author agreement. The final, definitive version of the article was published as:

Lockton, D., Harrison, D., Stanton, N.A. (2012) 'Models of the user: designers' perspectives on influencing sustainable behaviour'. Journal of Design Research Vol.10 No.1/2, pp.7-27, doi:10.1504/JDR.2012.046137

\begin{abstract}
Influencing more environmentally friendly and sustainable behaviour is a current focus of many projects, ranging from government social marketing campaigns, education and tax structures to designers' work on interactive products, services and environments. There is a wide variety of techniques and methods used, intended to work via different sets of cognitive and environmental principles. These approaches make different assumptions about 'what people are like': how users will respond to behavioural interventions, and why, and in the process reveal some of the assumptions that designers and other stakeholders, such as clients commissioning a project, make about human nature.

This paper discusses three simple models of user behaviour - the pinball, the shortcut and the thoughtful - which emerge from user experience designers' statements about users while focused on designing for behaviour change. The models are characterised using systems terminology and the application of each model to design for sustainable behaviour is examined via a series of examples.
\end{abstract}

Keywords: behaviour; sustainability; modelling; designers; patterns.

Reference to this paper should be made as follows: Lockton, D., Harrison, D. and Stanton, N.A. (2012) 'Models of the user: designers' perspectives on influencing sustainable behaviour', J. Design Research, Vol 10, No 1/2, pp.7-27.

Biographical notes: Dan Lockton is a $\mathrm{PhD}$ candidate at Brunel University and a Research Fellow at WMG, University of Warwick, specialising in design for behaviour change for social and environmental benefit. Over the last five years he has developed the Design with Intent toolkit, a resource of design patterns for influencing behaviour. At present, he works on Empower, a collaboration with More Associates aiming to reduce workplace energy use through connecting building users with energy data in more engaging ways. He studied Industrial Design Engineering at Brunel's former Runnymede design school, and a Master's in Technology Policy at the University of Cambridge. 
David Harrison is Professor of Design Research at Brunel University, and Lecturer in Sustainable Design and Environmentally Sensitive Design, specialising in sustainable design, innovative approaches to electronic manufacturing and printed electronics, via the Cleaner Electronics Research Group, which works on a range of environmentally sensitive design research. $\mathrm{He}$ worked for six years at the $\mathrm{BBC}$ as an Engineer, Researcher, Director and Assistant Producer, mainly on the BBC Computer Literacy Project. He also lectured in robotics for five years at the University of Portsmouth, and joined Brunel University as a Lecturer in Design in 1994.

Neville A. Stanton holds the Chair of Human Factors in Transport at the University of Southampton. He has written and edited over a dozen books and a hundred peer-reviewed journal papers on applications of human factors and ergonomics, and has helped organisations design new human-machine interfaces. Other work covers human reliability in high risk systems, evaluation of control room interfaces, work design, social organisation and environment, and product design. His research interests include situation awareness, task analysis, cognitive work analysis, human error, socio-technical systems, naturalistic decision making and human reactions in emergencies.

This paper is a revised and expanded version of a paper entitled 'Modelling the User: How design for sustainable behaviour can reveal different stakeholder perspectives on human nature', presented at 14th European Roundtable on Sustainable Consumption and Production (ERSCP) conference, presented at 14th European Roundtable
Delft, The Netherlands, October 2010.

\section{Introduction: design for sustainable behaviour}

There is growing recognition that "designers are in the behaviour business", as Frog Design's Robert Fabricant (2009) puts it, which means that research on behaviour change is increasingly being called upon in the design and development of new products and services, especially with environmentally and socially beneficial aims. Design for sustainable behaviour is emerging as a research area at the intersection of sustainable design and interaction design, applying insights from multiple disciplines to the problems of influencing more environmentally friendly use of products, services and environments (e.g., Combe et al., 2010; van Dam et al., 2010; Froehlich et al., 2010; Elias et al., 2009; Matsuhashi et al., 2009; Lilley, 2009; Bhamra et al., 2008; Pettersen and Boks, 2008; Wever et al., 2008; Lockton et al., 2008; Rodriguez and Boks, 2005). However, as Blevis (2007) puts it, "[i]t is easier to state the kinds of behaviours we would like to achieve from the perspective of sustainability than it is to account for how such behaviours may be adequately motivated".

For energy-using products and services, or those which consume other resources or create waste during operation, the 'use phase' of the life cycle - determined by the interaction between user and artefact - can make a significant contribution to the overall environmental footprint. As consumer products become increasingly efficient technologically, individual behavioural decisions (or the lack of them) are responsible for a significant proportion of household energy use: Dietz et al. (2009) estimate that $20 \%$ of direct household $\mathrm{CO}_{2}$ emissions in the USA could be saved through behaviour change, "with little or no reduction in household well-being", while Wood and Newborough (2003) and McCalley and Midden (2002) cite studies in the UK, USA and The Netherlands giving $26 \%-36 \%$ as the proportion of home energy usage due to user 
behaviour decisions. There is substantial variation: people do not all use energy in the same way, even in identical houses, with factors of two or more difference having been recorded, driven by householder behaviour (Sonderegger, 1978; Curtis, 1992-1993).

The behaviour component of the use phase may naïvely be seen as out of the hands of the designer or manufacturer, something that governments alone are best-placed to address, e.g., via social marketing techniques (Defra, 2008), taxation and legislation. However, in many ways, influencing behaviour can be seen as a design problem, concerned with how and why people interact with the products and systems around them, and how designed interventions might change this. As Redström (2006) puts it, "the intention to design the user experience is but the latest in a progression towards the user becoming the subject of design”. In a sustainability context, the subject here is, perhaps, 'making the user more efficient': design for sustainable behaviour starts to place the designer into the role of 'activist' (Thorpe, 2010; Fuad-Luke, 2009), designing with the intent to affect how people use and interact with things, rather than simply accommodating existing needs. It is still "a focus on the designed thing [or service] but from a different point of view” (Redström, 2006).

\subsection{Design with Intent: a catalogue of cross-disciplinary patterns}

Despite design's growing role in influencing sustainable behaviour, there is little guidance available for designers facing this sort of brief, which can be applied during the early stages of a project where discussions with clients and other stakeholders are likely to determine the approach taken. While user research methods - particularly focused on design for usability (e.g., van Kuijk, 2010) - have become central to the early stages of a user-centred design process and have expanded designers' understanding of the people for whom they are designing, designers do not have a clear set of use-cases for different behaviour-influencing design patterns, with information on their effectiveness. While this is never likely to be definitive, there is an opportunity for a guide which can help designers explore and think about how to apply and transpose research and practice from many disciplines.

As an attempt to go some way towards achieving this, the authors have developed the Design with Intent toolkit (Lockton et al., 2009, 2010a, 2010b, 2010c), a catalogue of design patterns for influencing user behaviour, illustrated with examples, and grouped into eight 'lenses' providing perspectives on human behaviour from different disciplines or fields of study, such as architecture, games and cognitive psychology. The pattern structure is influenced by the work of Alexander et al. (1977) and Tidwell (2005) as well as structured innovation methods such as TRIZ and IDEO's 'method card' collection. The DwI toolkit has evolved through a series of workshops with designers, students other stakeholders, applying it to both real and theoretical projects, covering a range of socially beneficial behaviour change applications in addition to the explicitly 'environmental' briefs.

One insight which emerged from running these workshops - and was commented on by participants - was that for each brief, the concepts generated by different participants seemed to embody different assumptions about 'what users are like'. Each behavioural intervention concept can be seen as a simple statement something like "people will do that if our design does this..." In some group sessions, discussions (if not quite arguments) ensued on what could be assumed about human nature when designing with 
the intention to influence behaviour, the key debate centring on how much people can be expected to think before behaving in a particular way, in a sustainability context but also with respect to other socially-related behaviours. While there was recognition that the population could perhaps be segmented into groups with different levels of interest in and attitudes towards the environment (compare Defra, 2008), and that individual people might be 'persuasion profiled' (Kaptein and Eckles, 2010) it was clear that unless a designed artefact were able to tailor its own behaviour to each segment of its user base automatically, it was going to be the case that each artefact embodied a particular model of how users think and behave. This model need not be generated by the designer him- or herself - it may well be the model that the client has used to understand the problem, or a model proposed by other project stakeholders. Nevertheless, the designer will have to apply it. As Froehlich et al. (2010) put it, "Even if it is not explicitly recognised, designers approach a problem with some model of human behaviour".

\subsection{Research questions: how do designers model users? - And what can be understood about design for sustainable behaviour from examining these models?}

It was decided to investigate the field of models of the user further to understand how these models relate to design for sustainable behaviour, and to the kinds of design patterns applied by designers. From the perspective of developing the toolkit further - to improve future versions - the purpose of the investigation was to characterise these models so that if possible, links could be drawn between the models and patterns which were especially relevant, to help designers explore the possibilities available.

The question of how designers 'see' or model users has been addressed previously in the science and technology studies literature (e.g., Woolgar, 1991; Hyysalo, 2006). This literature provides interesting critical perspectives, but they are not necessarily practically applicable to the situations in which the Design with Intent toolkit (for example) is being found useful - where designers are generating a range of intervention concepts in response to a brief about behaviour change, and are trying to reflect quickly on how they assume different interventions will work. More commonly in interaction design, Cooper's (1999) concept of personas is employed - essentially fictitious-but-useful single users with certain characteristics. The detail which a typical persona comprises is greater than that apposite to the toolkit brainstorming context, but there are common elements, and it is possible to imagine a 'behaviour persona' which profiles individual users in this way.

Thus, it was felt that to improve the toolkit, a simple, practical way of understanding designers' models of users, in terms of statements about behavioural patterns, assumptions or tendencies, would be useful. In the context of influencing behaviour (more specifically, more sustainable behaviour), a two-part research question was outlined: How do designers model users? - And what can be understood about design for sustainable behaviour from examining these models?

\section{Uncovering how designers model users}

In order to collect a representative range of designers' models of users relevant to a behaviour-change context, an informal exercise was carried out as an introductory part of two 'Design with Intent' workshops at UX London 2010, a design industry 
conference concerning user experience, an interaction design specialism focused strongly on understanding and shaping users' interactions with products and services. Two workshops, each with around 65 participants, were run on subsequent days, giving around 130 separate participants in total. Participants were practitioners rather than academics: user experience designers, interaction designers, human factors designers and information architects - primarily dealing with web, software and interactive service interface design.

\subsection{Method}

During the workshops, participants were asked to write down statements about 'what users are like' in the form 'users [verb] [rest of statement]' on Post-It notes (to allow anonymity, and facilitate the next stage of the process) - one statement per note, forming the main set of data for the study. It was suggested that these could be explicit assumptions that the participants may have heard while working on projects, such as '[Our] users won't read instructions' or implicit assumptions embedded in project briefs, such as 'reduce the number of options available [because 'users are bad at making decisions']'. The statements could be assumptions that participants themselves had made (and/or indeed believed) or ones which they had felt were being expressed by others during the design process (which they may have disagreed with). It was emphasised that as many ideas as possible should be included (along the lines of one of Osborn's (1953) primary recommendations for brainstorming: 'quantity is wanted').

Participants placed the Post-It notes on the walls of the room, and were asked to spend a couple of minutes reading others' ideas, before collectively attempting to create an affinity map (Kawakita, 1991; Scupin, 1997; Gray et al., 2010) by clustering similar statements together. After ten minutes of sorting, a group discussion followed about some of the clusters found, the attitudes revealed, and how common certain types of statements were, compared with others.

Following the workshops, the authors retyped the clustered Post-Its, simplifying the clusters slightly where duplication was apparent (or where the statements were not generalisable because they referred very specifically to aspects of a particular project, product or interface element that the participants had worked on), and gave each cluster a summary label also in the form 'users [verb] [rest of statement]' to represent best the plurality of statements contained within it.

\subsection{Results}

Participants produced 492 statements, equivalent to a mean of around 3.75 per person. Of these, 124 were not clusterable/generalisable, leaving 368, grouped into 25 clusters. Table 1 reproduces the detail of two of the clusters to illustrate the kind of statements produced by participants (space does not permit listing all 368 statements in this paper).

It is evident from some of the statements that the primarily digital/web focus of the participants' jobs may have led to an emphasis on elements of interaction with services (rather than products), which would perhaps not have been apparent with a different group of designers. Nevertheless, service-based systems - often including an online or 
networked component - are increasingly common in environmentally sensitive design, including in a behaviour-change context (e.g., Consolvo et al., 2007; Dillahunt et al., 2008; Shiraishi et al., 2009), so these statements are still valuable alongside the more generally applicable ones.

Table 1 Two of the 25 clusters of statements generated by participants

\begin{tabular}{ll}
$\begin{array}{l}\text { Users care about their social context } \\
\text { (19 statements) }\end{array}$ & \multicolumn{1}{c}{$\begin{array}{c}\text { Users know what they want } \\
\text { (14 statements) }\end{array}$} \\
\hline Users like to become experts & $\begin{array}{c}\text { Users are aware of their needs } \\
\text { Users are goal-oriented } \\
\text { Users want recognition }\end{array}$ \\
Users seek approval & $\begin{array}{l}\text { Users are looking for specific information } \\
\text { Users are motivated }\end{array}$ \\
Users want to be loved & Users are trying to reach a goal \\
Users want to be loved/liked & Users have a purpose \\
Users want to be noticed & Users have clear goals \\
Users want to share & Users have clear goals \\
Users will refer your services to others & Users know what they are doing \\
Users will want to do things that make them look & \\
good to family/friends/peers & Users know what they are looking for \\
Users will upload content or increase their & \\
contribution & Users know what they want \\
Users like to know what other users do & Users will find it, if they want it \\
Users like to please (in a test situation) & Users are task-focused \\
Users like to share stuff & Users are using our system to reach a goal \\
Users like to share things with their friends & \\
Users like to be part of a group & \\
Users like neighbour stories & \\
Users are influenced by their peers & \\
Users are people: people need people & \\
Users are social: people need people & \\
\hline
\end{tabular}

Table 2

Names of all 25 clusters of statements

\begin{tabular}{lllll}
\hline Users are stupid & $\begin{array}{l}\text { Users are } \\
\text { clever/thoughtful } \\
\text { and want to be } \\
\text { treated as such }\end{array}$ & $\begin{array}{l}\text { Users don't } \\
\text { read or notice } \\
\text { things }\end{array}$ & $\begin{array}{l}\text { Users will read } \\
\text { certain things }\end{array}$ & $\begin{array}{l}\text { Users like } \\
\text { feedback, } \\
\text { information } \\
\text { and analysis }\end{array}$ \\
$\begin{array}{l}\text { Users don't want } \\
\text { choice } \\
\text { choice }\end{array}$ & $\begin{array}{l}\text { Users don't } \\
\text { investigate } \\
\text { further }\end{array}$ & $\begin{array}{l}\text { Users want to } \\
\text { discover and } \\
\text { explore }\end{array}$ & $\begin{array}{l}\text { Users just want } \\
\text { to get on with } \\
\text { it }\end{array}$ \\
$\begin{array}{l}\text { Users want the } \\
\text { easiest way to do } \\
\text { things }\end{array}$ & $\begin{array}{l}\text { Users will see } \\
\text { patterns and learn } \\
\text { from them }\end{array}$ & $\begin{array}{l}\text { Users don't } \\
\text { know what } \\
\text { they want }\end{array}$ & $\begin{array}{l}\text { Users know } \\
\text { what they want }\end{array}$ & $\begin{array}{l}\text { Users care } \\
\text { about their } \\
\text { Users cannot or do } \\
\text { not make decisions } \\
\text { for themselves }\end{array}$ \\
$\begin{array}{l}\text { Users are } \\
\text { risk-averse/ } \\
\text { sceptical/nervous don't }\end{array}$ & $\begin{array}{l}\text { Users just want } \\
\text { 'bread and } \\
\text { circuses' } \\
\text { donderstand and }\end{array}$ & $\begin{array}{l}\text { Users are } \\
\text { averse to } \\
\text { change }\end{array}$ & $\begin{array}{l}\text { Users are } \\
\text { impatient/ } \\
\text { busy/tired }\end{array}$ \\
\hline
\end{tabular}


Table 2 lists all 25 clusters. A number of them essentially expressed opposite views, while others, though emphasising one aspect of human nature, were not necessarily incompatible with one another. Equally, many clusters could well overlap: they are not by any means mutually exclusive, or indeed collectively exhaustive, but they represent the kinds of statements designers actually made - or those they have heard from other stakeholders such as clients - about 'what users are like' in the context of developing new products and services. It is interesting to consider the balance of 'user-centredness' in the statements, given the predominance of the user-centred design paradigm in current design thinking: all the statements are inherently 'user-centred', but not all are particularly complimentary about users' abilities or tendencies. A personal observation from the authors - which will be discussed further in Section 3.4 - is that they can imagine using every one of the statements about themselves, at different times and in different contexts.

\subsection{Understanding the statements: modelling systems}

Each cluster of statements essentially represents a model of how users might behave in the context of interacting with a product or service (or indeed environment). These are not at the level of personas, but at a more abstracted 'system' level.

The behaviour of the system in use - whether product or service - is made up of behaviour which the designer can specify under different conditions (which might be termed the artefact system) coupled with user behaviour which is more difficult to specify (the human system). If the designer's aim is to shape the interaction (e.g., in our application, reducing the environmental impact of the use phase of a product), the best that he or she can do is to model the human system's behaviour under different conditions, coupled to the behaviour of the artefact system, and design the artefact system's behaviour to work with the assumed model of the human system, to engender the desired interaction.

Following this line of analysis, it is useful to consider existing work on systems modelling of interaction between users and technological artefacts. A promising direction comes from Dubberly et al. (2009), who have applied the work of systems theory pioneers such as Boulding (1956) and Pask (1976) to human-computer interaction, and presented a simplified set of interaction archetypes, each involving two systems interacting. Each of the two systems can be a linear (zeroth-order), self-regulating (first-order) or learning (second-order) cybernetic system. A linear system is 'open-loop' and can only react to a stimulus or input; a self-regulating system is closed-loop and adjusts its behaviour to match some goal (which it cannot alter itself); while a learning system comprises two nested self-regulating systems such that the second system can alter the goal of the first system.

While Dubberly et al. consider users (the human system) as primarily learning systems, the designers' statements in the clusters in Tables 1 and 2 suggest that designers do not always view users in this way. For example, 'users don't understand and don't want to think' models the human system very differently to 'users want to discover and explore'. Table 3 shows the nine permutations produced: this expands Dubberly et al.'s work slightly, by explicitly including reversed permutations of coupled systems such as $1-0$ as well as $0-1$ (since in the context under discussion, the order in which the models of the human- and artefact systems are coupled matters). 
Table 3 Permutations of artefact- and human-system models (see online version for colours)

\begin{tabular}{|c|c|c|c|c|}
\hline $\begin{array}{l}\text { Interaction } \\
\text { archetype }\end{array}$ & $\begin{array}{l}\text { Diagrammatic } \\
\text { representation }\end{array}$ & $\begin{array}{c}\text { Model of } \\
\text { artefact } \\
\text { system }\end{array}$ & $\begin{array}{l}\text { Model of } \\
\text { human } \\
\text { system }\end{array}$ & $\begin{array}{l}\text { Example statements } \\
\text { about human system } \\
\text { in this context }\end{array}$ \\
\hline $0-0$ & $\rightarrow$ & Linear & Linear & E.g., users are stupid \\
\hline $1-0$ & & Self-regulating & Linear & $\begin{array}{l}\text { E.g., users are not as } \\
\text { savvy as we are }\end{array}$ \\
\hline $2-0$ & & Learning & Linear & $\begin{array}{l}\text { E.g., users cannot or } \\
\text { do not make decisions } \\
\text { for themselves }\end{array}$ \\
\hline $0-1$ & & Linear & Self-regulating & $\begin{array}{l}\text { E.g., users want the } \\
\text { easiest way to do } \\
\text { things }\end{array}$ \\
\hline $1-1$ & & Self-regulating & Self-regulating & $\begin{array}{c}\text { E.g., users are } \\
\text { impatient/busy/tired }\end{array}$ \\
\hline $2-1$ & & Learning & Self-regulating & $\begin{array}{c}\text { E.g., users only look at } \\
\text { a few options }\end{array}$ \\
\hline $0-2$ & & Linear & Learning & $\begin{array}{c}\text { E.g., users are } \\
\text { clever/thoughtful and } \\
\text { want to be treated as } \\
\text { such }\end{array}$ \\
\hline $1-2$ & & Self-regulating & Learning & $\begin{array}{l}\text { E.g., users will see } \\
\text { patterns and learn } \\
\text { from them }\end{array}$ \\
\hline $2-2$ & & & Learning & $\begin{array}{c}\text { E.g., users like } \\
\text { feedback, information } \\
\text { and analysis }\end{array}$ \\
\hline
\end{tabular}

Notes: Example statements are drawn from the titles of the clusters in Table 2 and the individual designers' post-it notes discussed in Section 2.2. Red indicates the human system; blue the artefact system.

Source: Following Dubberly et al. (2009) 
It can be seen from the table that focusing on the way the human system is modelled, there are three groups (human system as linear, human system as self-regulating and human system as learning) of three archetypes each. How well do these map to the statements made by designers? In the context of thinking about people, what do terms such as 'self-regulating' really mean?

\subsection{Pinballs, shortcuts and thoughtfulness}

The limited context in which this paper is trying to understand how designers model users relates specifically to influencing users' behaviour. It makes sense, then, to consider the linear, self-regulating and learning archetypes with reference to this.

\subsubsection{The 'pinball' metaphor for linear models of the human system}

A linear human system implies a model of a user who only reacts simply to inputs, doing the same thing each time the same stimulus is applied, and does not think about any decisions. To influence this kind of user's behaviour, the designer may apply techniques such as forcing functions (Lewis and Norman, 1986) or control poka-yokes (Shingo, 1986), which treat deviations from the 'correct' behaviour as errors, and aim to prevent these errors absolutely, regardless of whether the user understands why. This linear approach can be seen as modelling users as something like pinballs to shunt around, ignoring any more nuanced interaction processes, and not taking into account any kind of feedback loop. Many other products and services have aspects where a degree of control is desired, often for safety or security reasons.

The interlock on a microwave door prevents using the oven with the door open, yet does not try to educate users as to why it is safer. It just silently structures behaviour: users follow the designers' behaviour specification without necessarily being aware of it. If a bank has a row of ATMs, it does not want customers at adjacent machines to stand too close together, so it spaces them far enough apart for this not to happen: the actual affordances of the system are designed so that only certain behaviours occur, regardless of whether users are even aware of how their behaviour is being influenced. Note that the pinball model is really shorthand for 'model users as no better than linear systems' even though all designers are aware that humans are really higher-order systems than this.

Two clusters in Table 2 which fit strongly with the pinball model are 'users are stupid' and 'users cannot or do not make decisions for themselves'. There are also a number of clusters which describe something close to this model, but perhaps crediting users with a slightly more nuanced behavioural response: 'users don't read or notice things', 'users don't investigate further', 'users just want 'bread and circuses'” and 'users don't know what they want'. In each of these cases, there is something else beyond the linear system of the pinball - it seems to credit users with some element of a mind of their own, even if the assumption is that this mind is not applied fully to behaviour. These cases will be discussed further in Section 2.4.4.

\subsubsection{The 'shortcut' metaphor for self-regulating models of the human system}

In the context of user behaviour, a self-regulating human system can perhaps be understood by drawing parallels between the kind of behaviour exhibited by the centrifugal 'fly-ball' governor James Watt employed on his steam engines [Maxwell, 
1868; also noted by Dubberly et al. (2009) as an archetypal 'mechanical' example of self-regulation], and the concept of bounded rationality - e.g., satisficing (Simon, 1956, 1969) and fast-and-frugal heuristics (Gigerenzer and Selten, 2001) - in which actors employ decision strategies to make a 'good enough' choice rather than expending largely unproductive effort in trying to 'optimise' their choices. In both cases, a 'stopping rule' is employed which prevents the system (human or mechanical) entering an inefficient state where energy is wasted: these are essentially conservative strategies.

Returning to our context, a self-regulating human system can thus be seen as a user who is boundedly rational, who makes choices to minimise energy or cognitive expenditure. This means wanting the fastest or easiest way to do things, making use of heuristics and cognitive biases (Tversky and Kahneman, 1974) such as social proof or the status quo bias and not wanting to have to think (Krug, 2006): this model is of a user who takes shortcuts rather than thinking deeply about problems and how to solve them. He or she makes decisions based on how choices are presented, makes use of stopping rules (even if not consciously expressed) and does not devote the same mental effort to engage with every decision faced. Clusters of statements matching this model most directly are 'users want the easiest way to do things', 'users don't want choice', 'users care about their social context', 'users are averse to change', 'users are impatient/busy/tired', 'users don't understand and don't want to think, users are lazy', 'users have a short attention span', 'users are money- or reward-driven' and 'users are self-centred'.

With both shortcuts and pinballs, defaults can be important. If something is presented as the default option - and so seems normative - whether double-sided printing in a dialogue box or a $30^{\circ} \mathrm{C}$ wash cycle on the washing machine, many users will probably stick with it. As Samuelson and Zeckhauser (1988) point out, the asymmetry between the 'present state' in any situation, and a change in behaviour means that the present state, the status quo, is more likely to be taken as the reference point: deviations from this regarded as riskier, less desirable, or simply too much effort. Whether defaults are consciously designed into systems or "established via historical precedent, perceptual salience, conspicuousness, or some other feature that qualitatively distinguishes one option from the rest" [Frederick, (2002), p.555], their existence can lead to a bias towards omission (as opposed to commission), not changing behaviour (or not doing anything at all).

\subsubsection{The 'thoughtful' term for learning models of the human system}

In a behaviour-change context, a learning human system can be seen as modelling users as thoughtful people, who think about what they are doing, and why, analytically - they are able to set and modify their own goals and are open to 'central route' persuasion (Petty and Cacioppo, 1981) through reasoned arguments about why some behaviours are better than others, maybe motivating them to change their attitudes about a subject as a precursor to changing their behaviour mindfully. These are users who can learn from their mistakes (and those of others) and change their behaviour accordingly.

Designers modelling users as thoughtful will probably be presenting them with information and feedback allowing them to explore the implications of what they're doing, and understand their impacts on the world. This is the case with many sustainable behaviour interventions such as educational campaigns about pro-environmental behaviour, much work on feedback with energy meters (e.g., Darby, 
2006) and so on. Most designers - indeed most people - probably like to model themselves as thoughtful, even though they know they don't always fit the model.

Some clusters matching this model are easy to identify: 'users are clever/thoughtful and want to be treated as such', 'users know what they want', 'users want choice', 'users will see patterns and learn from them', 'users want to discover and explore' and 'users like feedback, information and analysis'. There are, again, a few which seem to fall slightly short of the full 'thoughtful' characterisation, which will be examined in the next section.

\subsubsection{The pinball-shortcut-thoughtful spectrum}

It is clear that the models outlined above are not definitive: they are simply a way of understanding how to apply the different kinds of system archetypes in the context of design for behaviour change. For any interaction situation - any coupling of the human- and artefact systems - there is perhaps a spectrum of users matching the different models, some more than others. Thus designers can (and indeed probably should) assume variability across the range of the prospective users of the product/service/environment, since it will most likely be operated by users from across the pinball-shortcut-thoughtful spectrum.

For example, designing the $30^{\circ} \mathrm{C}$ wash cycle to be the default setting on a washing machine may represent a pinball model of some users, who will simply accept the setting without even considering that it can be changed; a shortcut model of other users, who know it can be changed but assume it is probably right (since it is the default, or is perceived to be too much effort to change); and a thoughtful model of another group of users, who will investigate other settings, treating the default as nothing more than a starting-point for exploration of the interface. Appreciating, or determining where on the spectrum different users will lie, and matching the artefact system models accordingly, seems crucial to effective design for sustainable behaviour, and there may be cases where different strategies can be employed together to take account of each model. Rather than producing (and perhaps selling) different products or services matched to each model, a system may offer a graduated set of 'levels' of interaction - an automatic variant embodying a pinball model, a presentation of options giving a clear recommendation or allowing the use of a quick decision heuristic for shortcut users, and a more detailed presentation of information for thoughtful users. Web services - where analytics can allow automated profiling of users' interaction behaviour (Kaptein and Eckles, 2010) - are especially suited to this kind of adaptation.

As part of a spectrum, the pinball, shortcut and thoughtful models can be treated as 'markers' rather than absolute categories. This allows more nuanced statements such as 'users don't investigate further' (mentioned in Section 2.4.1) to be positioned somewhere between models with which they share some characteristics (in this example, some users may not investigate further because they're 'pinballs', while others may not do it as they take whatever shortcuts they can, including avoiding extra investigation). Table 4 shows the 25 clusters of Table 2 distributed on the spectrum. 
Table 4 The 25 clusters of Table 2, distributed on the pinball-shortcut-thoughtful spectrum derived from Table 3

\begin{tabular}{|c|c|c|c|c|}
\hline Pinball & 2 & Shortcut & $<$ & Thoughtful \\
\hline $\begin{array}{l}\text { Users are } \\
\text { stupid }\end{array}$ & $\begin{array}{l}\text { Users don't } \\
\text { read or notice } \\
\text { things }\end{array}$ & $\begin{array}{c}\text { Users want the } \\
\text { easiest } \\
\text { way to do } \\
\text { things }\end{array}$ & $\begin{array}{l}\text { Users will } \\
\text { read certain } \\
\text { things }\end{array}$ & $\begin{array}{c}\text { Users are } \\
\text { clever/thoughtful } \\
\text { and want to be } \\
\text { treated as such }\end{array}$ \\
\hline \multirow{9}{*}{$\begin{array}{l}\text { Users cannot } \\
\text { or do not } \\
\text { make } \\
\text { decisions for } \\
\text { themselves }\end{array}$} & $\begin{array}{l}\text { Users don't } \\
\text { investigate } \\
\text { further }\end{array}$ & $\begin{array}{l}\text { Users } \\
\text { don't want } \\
\text { choice }\end{array}$ & $\begin{array}{c}\text { Users just } \\
\text { want to get on } \\
\text { with it }\end{array}$ & $\begin{array}{c}\text { Users know } \\
\text { what they } \\
\text { want }\end{array}$ \\
\hline & $\begin{array}{c}\text { Users just want } \\
\text { bread and } \\
\text { circuses }\end{array}$ & $\begin{array}{c}\text { Users care about } \\
\text { their social } \\
\text { context }\end{array}$ & $\begin{array}{c}\text { Users are } \\
\text { risk-averse/ } \\
\text { sceptical/nervous }\end{array}$ & $\begin{array}{l}\text { Users want } \\
\text { choice }\end{array}$ \\
\hline & $\begin{array}{l}\text { Users don't } \\
\text { know what } \\
\text { they want }\end{array}$ & $\begin{array}{l}\text { Users are } \\
\text { averse } \\
\text { to change }\end{array}$ & & $\begin{array}{c}\text { Users will see } \\
\text { patterns and learn } \\
\text { from them }\end{array}$ \\
\hline & & $\begin{array}{l}\text { Users are } \\
\text { impatient/ } \\
\text { busy/tired }\end{array}$ & & $\begin{array}{l}\text { Users want to } \\
\text { discover and } \\
\text { explore }\end{array}$ \\
\hline & & $\begin{array}{l}\text { Users don't } \\
\text { understand and } \\
\text { don't want } \\
\text { to think }\end{array}$ & & $\begin{array}{c}\text { Users like } \\
\text { feedback, } \\
\text { information and } \\
\text { analysis }\end{array}$ \\
\hline & & Users are lazy & & \\
\hline & & $\begin{array}{l}\text { Users have a } \\
\text { short attention } \\
\text { span }\end{array}$ & & \\
\hline & & $\begin{array}{c}\text { Users are } \\
\text { money- or } \\
\text { reward driven }\end{array}$ & & \\
\hline & & $\begin{array}{c}\text { Users are } \\
\text { self-centred }\end{array}$ & & \\
\hline
\end{tabular}

Note: The clusters in italics represent perhaps a 'prototypical' description of each model.

\section{Implications for design for sustainable behaviour}

As discussed in Section 1.2, all design happens with some model of the user in mind, and in designing to influence user behaviour, this potentially becomes even more important to consider. While it is outside the scope of this paper to review the whole field of 'sustainable behaviour' interventions to uncover the models designers have used, it is worth examining how the pinball-shortcut-thoughtful spectrum outlined above could be seen to manifest itself in some examples aiming to produce environmental benefit through behaviour change. 


\subsection{The pinball model and influencing more sustainable behaviour}

Manifestations of the pinball model in the context of influencing more sustainable behaviour centre around the ideas expressed by the 'users are stupid' and 'users cannot or do not make decisions for themselves' clusters (see Section 2.4.1). In Table 5, a range of example sustainable behaviour interventions using a pinball approach are listed, together with the DwI patterns they employ (see Section 1.1).

Table 5 Five examples of sustainable behaviour interventions taking a pinball model approach

\begin{tabular}{ll}
\hline Design with Intent patterns & Example pinball sustainable behaviour interventions \\
\hline Feature deletion & Removing standby buttons from television sets \\
Hiding things & Covering up heating controls to prevent users changing settings \\
Choice editing & Removing leaded petrol from sale \\
Interlock & System preventing air conditioning from operating if windows \\
& are open \\
Matched affordances & Eaton MEM BC3 bulb and fitting (see below) \\
\hline
\end{tabular}

Figure 1 Eaton MEM BC3 bulb and fitting (on the right) compared with standard bayonet bulb and fitting (on the left).
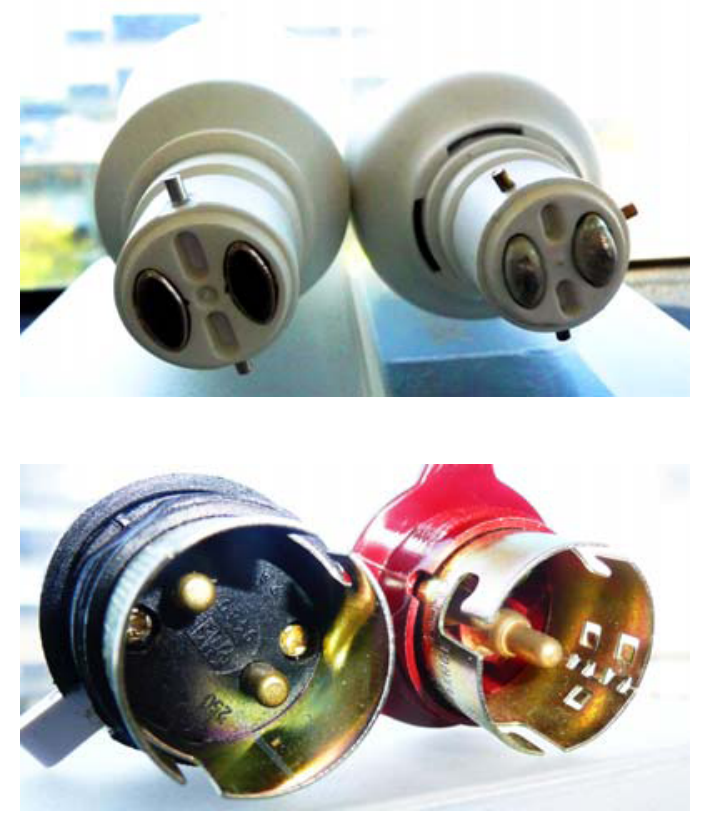
A pinball approach often involves legislation: interventions such as removing tungsten filament incandescent lightbulbs from sale (e.g., Commission of the European Communities, 2009) or the Eaton MEM BC3 system (Lockton, 2008) use patterns such as choice editing, matched affordances and format lock-in to force consumers to change their behaviour - the aim is not to provide users with a range of choices and help them choose what is best for them, but to cause absolute compliance with a target behaviour (knowingly or otherwise). The BC3 system (Figure 1) - effectively a 3-pin bayonet light fitting, and special 3-pin compact fluorescent bulbs to fit it - arose from Amendment L1 of the UK Building Regulations [Office of the Deputy Prime Minister, (2002), p.17], which from 2002 required all new residential properties to be fitted with a number of light fittings that could only accept 'low energy' bulbs', in order to 'force' householders not to use incandescent filament bulbs (which were not available in the 3-pin format). In this sort of situation, treating all users as pinballs in an attempt to force behaviour change risks provoking significant reactance, which could even 'poison' user attitudes towards other environmentally beneficial products or design changes.

\subsection{The shortcut model and influencing more sustainable behaviour}

One consequence of the shortcut model especially relevant to sustainable behaviour is how it relates to the concept of energy literacy. Without thinking or understanding too much about energy use, people tend to overestimate the energy used by some appliances where it is very visible (e.g., lighting) compared with invisible uses such as air conditioning (Kempton and Montgomery, 1982; Attari et al., 2010). This immediately suggests redesigning devices to incorporate obvious, vivid displays of energy use, which could be feedback on actual energy use (fitting more closely with a thoughtful model) or simply a reminder that energy is being used - an ultra-simple kind of feedback. Along these lines, Giacomin (2010) has discussed the idea of an 'energy sixth sense'.

It could be that a display 'translates' all environmental impact into some single vivid shortcut 'measure' which is intended to have an emotional impact on householders, such as Shiraishi et al.'s (2009) EcoIsland game, which "visualises the user's current eco-friendly behaviour as an island shared by his/her family members", with the island sinking if the family does not work together to reduce their $\mathrm{CO}_{2}$ impact. A trial with six families led to increases in environmental awareness but not significant changes in actual behaviour.

In this context, Wilson and Dowlatabadi (2007) note that "emphasising one particularly salient or emotional attribute may influence a decision more than providing information on all attributes". There is a risk here of oversimplification, of conflating unrelated environmental behaviours and impacts into a 'measure' which is nothing of the sort, without educating users about anything deeper, but it may be that designed shortcuts which just allow users to make rapid, satisficing decisions about what action to take (and in the process reduce their environmental impact) can be effective. This is the sort of thinking behind Thaler and Sunstein's (2008) Nudge and a number of interventions using principles from behavioural economics; Table 6 gives some examples of interventions assuming a shortcut model of the user, with the relevant DwI patterns identified. 
Table 6 Four examples of sustainable behaviour interventions taking a shortcut model approach

\begin{tabular}{|c|c|}
\hline Design with Intent patterns & Example shortcut sustainable behaviour interventions \\
\hline Simplicity & $\begin{array}{l}\text { The EcoButton is a large, prominent USB button which allows } \\
\text { users to put a computer into a low-power mode with a single } \\
\text { press. }\end{array}$ \\
\hline Perceived affordances & $\begin{array}{l}\text { Duffy and Verges (2009) found that recycling bins with specialised } \\
\text { apertures in the lids, 'matched' to different recyclable items } \\
\text { (e.g., a round hole for bottles) increased recycling rates by } 34 \% \\
\text { (for beverage containers) overall and reduced the 'wrong' } \\
\text { non-recyclable items entering the waste stream by } 95 \% \text { compared } \\
\text { with bins without specialised lids. They suggest three possible } \\
\text { mechanisms to explain the finding, all of which involve users } \\
\text { taking 'shortcuts'. }\end{array}$ \\
\hline Portions & $\begin{array}{l}\text { Unilever's 'portion' detergent tablets are in part an attempt to } \\
\text { ensure that users do not use more (or less) than the optimum } \\
\text { amount of powder for each wash (Lilley et al., 2005), by } \\
\text { presenting the 'right' amount in a convenient form. It is possible to } \\
\text { override this, of course, but the 'shortcut' is to accept the portion } \\
\text { provided. }\end{array}$ \\
\hline Social proof & $\begin{array}{l}\text { OPOWER (e.g., Allcott, 2010), building on the work of } \\
\text { Schultz et al. (2007), gives electricity and gas customers } \\
\text { 'neighbourhood comparisons' of their energy use. }\end{array}$ \\
\hline
\end{tabular}

\subsection{The thoughtful model and influencing more sustainable behaviour}

Thoughtful users are assumed to think about what they are doing - and why - and learn from their experiences and those of other people. In the context of sustainable behaviour, this may take the form of presenting users with educational information exhorting behaviour change, and/or feedback on energy use and environmental impact allowing them to explore the implications of what they are doing (or could do better), and understand the consequences of behaviour.

A key point here is that a thoughtful user model of behaviour change assumes that where people profess the intention to behave in a more environmentally beneficial way, they will actually be able to do this in practice. This is not necessarily the case: Guerin et al. (2000), reviewing 45 US studies of residential energy use from 1975-1998 note that it was demographic characteristics of the occupants and their homes (e.g., age, income, home ownership, education, number of occupants, and physical size of the house) that were actually the better predictors of environmentally beneficial behaviour and reduced energy usage, rather than occupants' professed attitudes in favour of conservation. Table 7 gives some examples of sustainable behaviour interventions assuming a thoughtful model of the user, with the relevant DwI patterns identified. 
Table 7 Four examples of sustainable behaviour interventions taking a thoughtful model approach

\begin{tabular}{ll}
\hline Design with Intent patterns & Example thoughtful sustainable behaviour interventions \\
\hline Feedback through form & $\begin{array}{l}\text { The 'Aware' puzzle switch, produced by Stockholm's Interactive } \\
\text { Institute, is a patterned light switch which is visibly disordered } \\
\text { when switched on. } \\
\text { Real-time feedback }\end{array}$ \\
$\begin{array}{l}\text { McCalley and Midden (2002), focusing on washing machine use, } \\
\text { gave users immediate feedback on the energy (kWh) used per load, } \\
\text { and allowed them to set goals for reducing their usage }\end{array}$ \\
$\begin{array}{l}\text { Dillahunt et al. (2008) produced a game with a 'virtual polar bear' } \\
\text { standing on a shrinking (or growing) ice floe to represent the } \\
\text { effects of participants' (self-reported) environmentally responsible } \\
\text { behaviour. }\end{array}$ \\
$\begin{array}{l}\text { CarbonCulture, by More Associates (Figure 2) is being used by a } \\
\text { number of UK government departments to make energy use data, } \\
\text { trends and costs available publicly - allowing public scrutiny of } \\
\text { civil servants' energy behaviour. }\end{array}$ \\
\hline
\end{tabular}

Figure 2 More Associates' CarbonCulture energy display for the UK Government's Cabinet Office (see online version for colours)

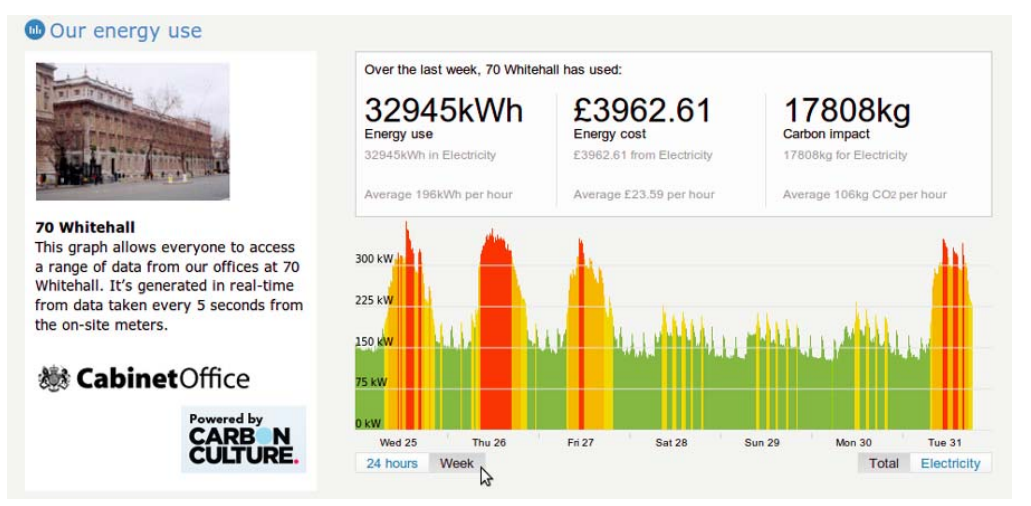

\subsection{Discussion and conclusions}

This paper has discussed simple models of user behaviour emerging from statements by designers taking part in a workshop on influencing behaviour through design. By clustering similar statements and using systems concepts to provide structure, it was possible to arrive at a spectrum of ways in which designers model users, broadly divisible into three models. Then, by examining each model and its implications if applied to the design of products and services, some of the ramifications for design for sustainable behaviour have been drawn out and discussed further. 


\subsubsection{How do designers model users? What can be understood about design for sustainable behaviour from examining these models?}

Returning to the research questions introduced in Section 1.2, assumptions about how users may behave - expressed as 368 statements in the form 'users [verb] [rest of statement]' - were arranged into 25 clusters representing similar views; they were not exhaustive, but they represented the kinds of statements designers actually made (or those they have heard from other stakeholders such as clients) about 'what users are like' in the context of developing new products and services. From these clusters, applying a modified version of a systems analysis for human-computer interaction developed by Dubberly et al. (2009), three main 'marker' models emerged: the 'pinball', 'shortcut' and 'thoughtful' models of how users behave and thus how their behaviour can be influenced through design. The implications and possibilities of each model were discussed in the context of influencing more sustainable user behaviour through design, via a number of examples. The recommendation is that designers probably should assume variability across the range of the prospective users of a product or service, but that certain design strategies are better suited to each of the three models from the perspective of influencing behaviour. A personal observation from the authors is that the 'users [verb] [rest of statement]' statements made by participants, while some of them were relatively uncomplimentary towards users, all represent statements which at different times and in different contexts, anyone could say about him or herself with a degree of truth: the models are not a semi-permanent way of segmenting the population, but representative of assumptions about behaviour at a particular time or in a particular interaction or decision-making situation.

The models are most appropriately considered at the early stages of the design process, in parallel with concept generation, and so the process of reflecting on (and perhaps challenging) the assumptions being made about user behaviour can be seen as an additional element of the Design with Intent toolkit. For example, if most of the ideas being generated are representative of a particular model of behaviour - say, assuming a pinball-like model of the user - introducing the provocation of considering a different way of thinking about people (say, the thoughtful model) could spur the creation of another field of possible ideas for influencing behaviour. Even the step of a design team recognising which model of the user is dominating a client's thinking could be an important trigger for considering other models which might also be worth investigating.

\subsubsection{Limitations of this study}

The study has many limitations: while the number of participants was high, the workshop setting, at an industry conference, was not controlled, and the process of clustering the statements (both by participants themselves and as extended by the authors) introduced a large degree of subjectivity. The participants were all interaction, web and user experience design practitioners, so this bias is to some extent reflected in the statements. The study is better seen as an exploration of ideas in this direction than a definitive statement on models of the user.

The real test of how appropriate the different models are in particular sustainable behaviour situations is the change in user behaviour that results in practice. The vibrancy of the emerging design for sustainable behaviour field is testament to the fact that definitive answers about what works and what doesn't, when and why, have not yet been 
found for many domains. Indeed, if in reality the users of a new product or service display a multiplicity or spectrum of models, it may never be possible to design artefacts which can match all of them at once. However, the models developed in this paper from statements about the nature of users, made by designers, can certainly be seen to provide an additional perspective on how the design process can work for sustainable behaviour problems.

\subsubsection{Further work}

This paper contributes to ongoing design research aiming to characterise and structure the 'strategy space' for influencing user behaviour for environmental or social benefit (e.g., Zachrisson and Boks, 2010) by linking some of these design strategies to models of user behaviour. However, it does this by inference rather than through testing these links empirically. The authors are continuing to do work exploring designers' models of users, and also users' mental models of the technology around them via a series of ethnographic studies focused specifically on energy use, and how matching and shifting these models through design could work to influence behaviour for environmental benefit.

\section{References}

Alexander, C., Ishikawa, S., Silverstein, M., Jacobson, M. et al. (1977) A Pattern Language: Towns, Buildings, Construction, Oxford University Press, New York.

Allcott, H. (2010) 'Social norms and energy conservation', MIT Working Paper.

Attari, S., DeKay, M., Davidson, C. and Bruine de Bruin, W. (2010) 'Public perception of energy consumption and savings', Proceedings of the National Academy of Sciences, Vol. 107, No. 37, pp.16054-16059.

Bhamra, T., Lilley, D. and Tang, T. (2008) 'Sustainable use: changing consumer behaviour through product design', Proceedings of Changing the Change: Design Visions, Proposals and Tools, Turin, Italy.

Blevis, E. (2007) 'Sustainable interaction design: invention \& disposal, renewal \& reuse', Proceedings of CHI 2007 - Design Theory, San Jose, California, USA.

Boulding, K.E. (1956) 'General systems theory - the skeleton of science', Management Science, Vol. 2, No. 3, pp.197-208.

Combe, N., Harrison, D., Dong, H., Craig, S. and Gill, Z. (2010) 'Assessing the number of users who are excluded by domestic heating controls', International Journal of Sustainable Engineering, in press.

Commission of the European Communities (2009) 'Commission Regulation (EC) No. 244/2009 of 18 March 2009 implementing Directive 2005/32/EC of the European Parliament and of the Council with regard to ecodesign requirements for non-directional household lamps', Official Journal of the European Union, L76, 24.3.2009, pp.3-16.

Consolvo, S., Paulos, E. and Smith, I. (2007) 'Mobile persuasion for everyday behavior change', in B.J. Fogg and D. Eckles (Eds.): Mobile Persuasion: 20 Perspectives on the Future of Behavior Change, Stanford Captology Media, Stanford.

Cooper, A. (1999) The Inmates Are Running the Asylum: Why High-tech Products Drive us Crazy and How to Restore the Sanity, Sams, Indianapolis.

Curtis, T. (1992-1993) Greenhouse Programme: Report on the Heating Advice Project Carried Out on the Packington and Market Estates 1991/92 and 1992/93, Energy Information Centre, Islington Council, London.

Darby, S. (2006) The Effectiveness of Feedback on Energy Consumption: A Review for Defra of the Literature on Metering, Billing and Direct Displays, Environmental Change Institute, Oxford. 
Defra (2008) A Framework for Pro-Environmental Behaviours, Defra, London.

Dietz, T., Gardner, G., Gilligan, J., Stern, P. and Vandenberghe, M. (2009) 'Household actions can provide a behavioral wedge to rapidly reduce US carbon emissions', Proceedings of the National Academy of Sciences, Vol. 106, No. 44, pp.18452-18456.

Dillahunt, T., Becker, G., Mankoff, J. and Kraut, R. (2008) 'Motivating environmentally sustainable behavior changes with a virtual polar bear', Pervasive 2008 Workshop on Pervasive Persuasive Technology and Environmental Sustainability, Sydney, Australia.

Dubberly, H., Haque, U. and Pangaro, P. (2009) 'What is interaction? Are there different types?', ACM Interactions, Vol. 16, No. 1, pp.69-75.

Duffy, S. and Verges, M. (2009) 'It matters a hole lot: perceptual affordances of waste containers influence recycling compliance', Environment and Behavior, Vol. 41, No. 5, pp.741-749.

Elias, E.W., Dekoninck, E.A. and Culley, S.J. (2009) 'Designing for 'use phase' energy losses of domestic products', Proceedings of the Institution of Mechanical Engineers Part B - Journal of Engineering Manufacture, Vol. 223, No. 1, pp.115-120.

Fabricant, R. (2009) 'Behaving badly in Vancouver. Design mind’, February 11 2009, Frog Design, San Francisco, available at http://designmind.frogdesign.com/blog/behaving-badly-invancouver.html (accessed on 1 September 2010).

Frederick, S. (2002) 'Automated choice heuristics’, in Gilovich, T., Griffin, D. and Kahneman, D. (Eds.): Heuristics and Biases, Cambridge University Press, New York.

Froehlich, J., Findlater, L. and Landay, J. (2010) 'The design of eco-feedback technology', Proceedings of CHI 2010, Atlanta, Georgia, USA

Fuad-Luke, A. (2009) Design Activism: Beautiful Strangeness for a Sustainable World, Earthscan, London.

Giacomin, J. (2010) Thermal: Seeing the World Through 21st Century Eyes, Papadakis, London.

Gigerenzer, G. and Selten, R. (2001) 'Rethinking rationality', in G. Gigerenzer and R. Selten (Eds.): Bounded Rationality: The Adaptive Toolbox, MIT Press, Cambridge, MA.

Gray, D., Brown, A. and Macanufo, J. (2010) Gamestorming: A Playbook for Innovators, Rulebreakers and Changemakers, O’Reilly, Sebastopol.

Guerin, D.A., Yust, B.L. and Coopet, J.G. (2000) 'Occupant Predictors of household energy behavior and consumption change as found in energy studies since 1975', Family and Consumer Sciences Research Journal, Vol. 29, No. 1, pp.48-80.

Hyysalo, S. (2006) 'Representations of use and practice-bound imaginaries in automating the safety of the elderly', Social Studies of Science, Vol. 36, No. 4, pp.599-626.

Kaptein, M. and Eckles, D (2010) 'Selecting effective means to any end: futures and ethics of persuasion profiling', Proceedings of Persuasive Technology: Fifth International Conference, Persuasive 2010, Copenhagen, Denmark

Kawakita, J. (1991) The Original KJ Method, revised ed., Kawakita Research Institute, Tokyo.

Kempton, W. and Montgomery, L. (1982) 'Folk quantification of energy’, Energy, Vol. 7, No. 10, pp.817-827.

Krug, S. (2006) Don't Make Me Think! A Common Sense Approach to Web Usability, 2nd ed., New Riders, Berkeley.

Lewis, C. and Norman, D.A. (1986) 'Designing for error', in D.A. Norman and S.W. Draper (Eds.): User Centered System Design, Lawrence Erlbaum, Hillsdale.

Lilley, D. (2009) 'Design for sustainable behaviour: strategies and perceptions', Design Studies, Vol. 30, No. 6, pp.704-720.

Lilley, D., Lofthouse, V. and Bhamra, T. (2005) 'Towards instinctive sustainable product use', Proceedings of 2nd International Conference, Sustainability: Creating the Culture, Aberdeen, Scotland. 
Lockton, D. (2008) 'How to fit a normal bulb in a BC3 fitting and save £10 per bulb', Design with Intent Blog, 21 July available at http://architectures.danlockton.co.uk/2008/07/21/ how-to-fit-a-normal-bulb-in-a-bc3-fitting/ (accessed on 1 September 2010).

Lockton, D., Harrison, D. and Stanton, N.A. (2008) 'Making the user more efficient: design for sustainable behaviour', International Journal of Sustainable Engineering, Vol. 1, No. 1, pp.3-8.

Lockton, D., Harrison, D. and Stanton, N.A. (2009) Design for Behaviour Change: The Design with Intent Toolkit v.0.9, Brunel University, Uxbridge.

Lockton, D., Harrison, D. and Stanton, N.A. (2010a) 'The Design with Intent method: a design tool for influencing user behaviour’, Applied Ergonomics, Vol. 41, No. 3, pp.382-392.

Lockton, D., Harrison, D. and Stanton, N.A. (2010b) 'Concept generation for persuasive design', Poster proceedings of Persuasive Technology: Fifth International Conference, Persuasive 2010, Copenhagen, Denmark.

Lockton, D., Harrison, D. and Stanton, N.A. (2010c) Design with Intent: 101 Patterns for Influencing Behaviour Through Design v.1.0, Equifine, Windsor.

Matsuhashi, N., Kuijer, L. and de Jong, A. (2009) 'A culture-inspired approach to gaining insights for designing sustainable practices’, Proceedings of EcoDesign 2009, Sapporo, Japan.

Maxwell, J.C. (1868) 'On governors’, Proceedings of the Royal Society, Vol. 100.

McCalley, L.T. and Midden, C.J.H. (2002) 'Energy conservation through product-integrated feedback: the roles of goal-setting and social orientation', Journal of Economic Psychology, Vol. 23, No. 5, pp.589-603.

Office of the Deputy Prime Minister (2002) 'Approved Document L1', Conservation of Fuel and Power, available at http://www.planningportal.gov.uk/uploads/br/BR_PDF_ADL1_2002.pdf (accessed on 1 September 2010).

Osborn, A.F. (1953) Applied Imagination, Scribner's, Oxford.

Pask, G. (1976) Conversation Theory: Applications in Education ad Epistemology, Elsevier, New York.

Pettersen, I.N. and Boks, C. (2008) 'The ethics in balancing control and freedom when engineering solutions for sustainable behaviour', International Journal of Sustainable Engineering, Vol. 1, No. 4, pp.287-297.

Petty, R.E. and Cacioppo, J.T. (1981) Attitudes and Persuasion: Classic and Contemporary Approaches, William C. Brown, Dubuque.

Redström, J. (2006) 'Towards user design? On the shift from object to user as the subject of design', Design Studies, Vol. 27, No. 2, pp.123-139.

Rodriguez, E. and Boks, C. (2005) 'How design of products affects user behaviour and vice versa: the environmental implications’, Proceedings of Ecodesign 2005, Tokyo, Japan.

Samuelson, W. and Zeckhauser, R. (1988) 'Status quo bias in decision making', Journal of Risk and Uncertainty, Vol. 1, No. 1, pp.7-59.

Schultz, P.W., Nolan, J.M., Cialdini, R.B., Goldstein, N.J. and Griskevicius, V. (2007) 'The constructive, destructive, and reconstructive power of social norms', Psychological Science, Vol. 18, No. 5, pp.429-434.

Scupin, R. (1997) 'The KJ method: a technique for analyzing data derived from Japanese ethnology', Human Organization, Vol. 56, No. 2, pp.233-237.

Shingo, S. (1986) Zero Quality Control: Source Inspection and the Poka-Yoke System, Productivity Press, Portland.

Shiraishi, M., Washio, Y., Takayama, C., Lehdonvirta, V., Kimura, H. and Nakajima, T. (2009) 'Using individual, social and economic persuasion techniques to reduce $\mathrm{CO} 2$ emissions in a family setting', Proceedings of Persuasive Technology: Fourth International Conference, Persuasive 2009, Claremont, California. 
Simon, H.A. (1956) 'Rational choice and the structure of the environment', Psychological Review, Vol. 63, No. 2, pp.129-138.

Simon, H.A. (1969) The Sciences of the Artificial, MIT Press, Cambridge, MA.

Sonderegger, R.C. (1978) 'Movers and stayers: the residents' contribution to variation across houses in energy consumption for space heating', in R.H. Socolow (Ed.): Saving Energy in the Home, Princeton's Experiments at Twin Rivers, pp.207-230, Ballinger, Cambridge, MA.

Thaler, R.H. and Sunstein, C.R. (2008) Nudge: Improving Decisions about Health, Wealth, and Happiness, Yale University Press, New Haven.

Thorpe, A. (2010) 'Design’s role in sustainable consumption', Design Issues, Vol. 26, No. 2, pp.3-16

Tidwell, J. (2005) Designing Interfaces, O’Reilly, Sebastopol.

Tversky, A. and Kahneman, D. (1974) 'Judgment under uncertainty: heuristics and biases', Science, Vol. 185, pp.1124-1131.

van Dam, S.S., Bakker, C.A. and van Hal, J.D.M. (2010) 'Home energy monitors: impact over the medium-term', Building Research \& Information, Vol. 38, No. 5, pp.458-469.

van Kuijk, J. (2010) 'Recommendations for usability in practice (version 1.0)', available at http://uselog.oli.tudelft.nl/publications/Recommendations-VanKuijk.pdf (accessed on 1 May 2011).

Wever, R., van Kuijk, J. and Boks, C. (2008) 'User-centred design for sustainable behaviour', International Journal of Sustainable Engineering, Vol. 1, No. 1, pp.9-20.

Wilson, C. and Dowlatabadi, H. (2007) 'Models of decision making and residential energy use', Annual Review of Environment and Resources, Vol. 32, pp.169-203.

Wood, G. and Newborough, M. (2003) 'Dynamic energy-consumption indicators for domestic appliances: environment, behaviour and design', Energy \& Buildings, Vol. 35, No. 8, pp.821-841.

Woolgar, S. (1991) 'Configuring the user: the case of usability trials', in Law, J. (Ed.): A Sociology of Monsters: Essays on Power, Technology and Domination, Routledge, London.

Zachrisson, J. and Boks, C. (2010) 'When to apply different design for sustainable behaviour strategies?', Proceedings of Knowledge Collaboration \& Learning for Sustainable Innovation, ERSCP-EMSU Conference, Delft, The Netherlands, October. 